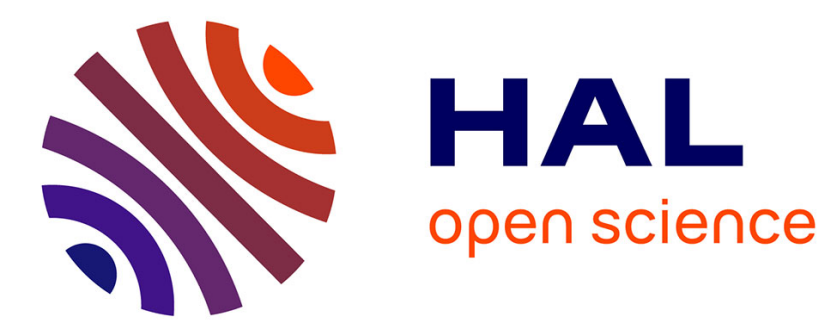

\title{
High resolution spectroscopy of the hydrogen atom - III. Wavelength comparison and Rydberg constant determination
}

\author{
J.C. Garreau, M. Allegrini, L. Julien, F. Biraben
}

\section{- To cite this version:}

J.C. Garreau, M. Allegrini, L. Julien, F. Biraben. High resolution spectroscopy of the hydrogen atom

- III. Wavelength comparison and Rydberg constant determination. Journal de Physique, 1990, 51 (20), pp.2293-2306. 10.1051/jphys:0199000510200229300 • jpa-00212529

HAL Id: jpa-00212529

https://hal.science/jpa-00212529

Submitted on 1 Jan 1990

HAL is a multi-disciplinary open access archive for the deposit and dissemination of scientific research documents, whether they are published or not. The documents may come from teaching and research institutions in France or abroad, or from public or private research centers.
L'archive ouverte pluridisciplinaire HAL, est destinée au dépôt et à la diffusion de documents scientifiques de niveau recherche, publiés ou non, émanant des établissements d'enseignement et de recherche français ou étrangers, des laboratoires publics ou privés. 
Classification

Physics Abstracts

$35.10-06.20 \mathrm{~J}-32.80 \mathrm{~K}$

\title{
High resolution spectroscopy of the hydrogen atom. III. Wavelength comparison and Rydberg constant determination
}

\author{
J.C. Garreau (*), M. Allegrini(**), L. Julien and F. Biraben
}

Laboratoire de Spectroscopie Hertzienne de l'ENS $\left({ }^{* * *}\right)$, Université Pierre et Marie Curie, 4 place Jussieu, Tour 12, E01 75252 Paris Cedex 05, France.

(Received 2 February 1990, revised 15 June 1990, accepted 27 June 1990)

Résumé. - Cet article est le dernier d'une série de trois donnant une description détaillée de notre mesure récente de la constante de Rydberg. Nous y décrivons soigneusement la méthode de mesure des longueurs d'onde. Les longueurs d'onde des trois transitions à deux photons 2S-8D, 2S-10D et 2S-12D dans l'hydrogène et le deutérium sont comparées à celle d'un laser He-Ne stabilisé sur l'iode, laser qui est actuellement la meilleure reférence dans le domaine optique. Cette comparaison est faite à l'aide d'un étalon Fabry-Perot de grande stabilité. Les déphasages à la réflexion sont pris en compte en changeant la longueur de cette cavite ("metthode des miroirs virtuels"). Pour mesurer le déphasage de Fresnel nous étudions la différence de fréquence entre le premier mode transverse et le mode fondamental de cette cavite. A partir des six longueurs d'onde mesurées, nous déduisons une nouvelle valeur de la constante de Rydberg $R_{\infty}=109737,315709(18) \mathrm{cm}^{-1}$, la plus précise à l'heure actuelle. A partir des déplacements isotopiques entre l'hydrogène et le deutérium nous déduisons aussi une valeur pour le rapport de masse entre le proton et l'électron : $m_{\mathrm{p}} / m_{\mathrm{e}}=1836.15259$ (24).

\begin{abstract}
This paper is the last of a series giving a detailed description of our recent determination of the Rydberg constant. Here we carefully describe the wavelength comparison procedure. The wavelengths of the three two-photon transitions 2S-8D, 2S-10D, and 2S-12D in hydrogen and deuterium are compared to that of an $I_{2}$-stabilized He-Ne laser which is the present best reference in the optical domain. The key of this comparison is a high stability Fabry-Perot cavity etalon. The reflective phase shifts are taken into account by changing the length of this cavity ("virtual mirrors method"). In order to measure the Fresnel phase shift we study the frequency difference between the first transverse mode and the fundamental mode of the cavity. From the six measured wavelengths we deduce a new value for the Rydberg constant, $R_{\infty}=109737.315709(18) \mathrm{cm}^{-1}$, currently the most precise one. The H-D isotopic shifts have been also measured and a value for the proton-to-electron mass ratio is deduced: $m_{\mathrm{p}} / m_{\mathrm{e}}=1836.15259(24)$.
\end{abstract}

(*) Present address: C.N.E.T., 196 Av. Henri Ravera, 92220 Bagneux, France.

$\left(^{* *}\right)$ Permanent address: Dipartimento di Fisica, Università di Pisa, Piazza Torricelli 2, 56100 Pisa, Italy.

$\left({ }^{* * *}\right)$ Laboratoire de l'Ecole Normale Supérieure et de l'Université Pierre et Marie Curie, associé au CNRS (URA 18). 


\section{Introduction.}

This paper is the last of a series of three (referred as papers I, II and III), giving a complete description of our recent determination of the Rydberg constant [1] . Our method is to measure the wavelengths of the $2 S-n D$ Doppler-free two photon transitions in an atomic beam of hydrogen or deuterium $n=8,10,12$. In paper I [2] , we have described the principle of our experiment and the experimental procedure used to observe lines as narrow as $600 \mathrm{kHz}$. In paper II [3] , we have carefully analyzed the lineshape of the two-photon transitions. As a result we know the atomic frequency positions with respect to a very stable reference cavity (FPR).

We describe now the measurement of the Rydberg constant. In section 2 we present the wavelength measurements, and in section 3 we describe the determination of the Rydberg constant.

\section{Wavelength measurement.}

2.1 STANDARD LASER - The transition wavelength is measured by interferometric techniques based on the comparison of our dye laser wavelength with the one of an $\mathrm{I}_{2}-$ stabilized He-Ne laser at $633 \mathrm{~nm}$. This He-Ne laser is the best reference in the optical domain since its frequency has been measured with respect to the cesium clock [4]. In fact we have two $\mathrm{I}_{2}$ - stabilized He-Ne lasers which are continuously compared and running with an $\mathrm{I}_{2}$ cold-finger temperature of $16^{\circ} \mathrm{C}$ and a modulation peak-to peak amplitude of $5 \mathrm{MHz}$. In order to check these reference lasers, we have made a frequency comparison with a standard He-Ne laser of the Institut National de Metrologie (INM). This comparison was made every day at the beginning and at the end of the experiment. The frequency difference value between the INM laser (stabilized on the d hyperfine component of the ${ }^{127} I_{2} 11-5 R(127)$ transition) and ours one (stabilized on the $f$ component) was 26.195 (5) $\mathrm{MHz}$ (mean of the data obtained during about a month). Taking into account the value for this difference $(26.224 \mathrm{MHz}$ [5] ), we deduce that our laser was $+29 \mathrm{kHz}$ shifted with respect to the INM one. The INM laser has been previously compared with the one of the Bureau International des Poids et Mesures (laser BIPM 2). With respect to this laser the INM laser was $-23 \mathrm{kHz}$ shifted [6]. Finally our $\mathrm{I}_{2}$-stabilized laser is $+6 \mathrm{kHz}$ shifted with respect to the BIPM one. We have assumed that the frequency of the BIPM laser (stabilized on the $i$ component) is as measured by D.A. Jennings et al. [4] with a $1.6 \times 10^{-10}$ relative uncertainty:

$$
\nu_{i}=473612214827 \mathrm{kHz}
$$

Taking into account the value for the $i-f$ splitting $(138.892 \mathrm{MHz}[5])$, we deduce the frequency value for the $f$ component of our $\mathrm{I}_{2}$-stabilized He-Ne laser:

$$
\nu_{f}=473612353725 \mathrm{kHz}
$$

We have used this value for the wavelength measurements and for the Rydberg constant determination.

2.2 INTERFERENCE APPARATUS - The key element for the interferometric comparison is a nondegenerate Fabry-Perot etalon (FPE) kept under a vacuum lower than $10^{-6}$ mbar. In these conditions the error due to the index variation between the compared wavelengths is reduced to about $10^{-15}$. This optical cavity is built with two silver coated mirrors, one flat and the other spherical $(R=60 \mathrm{~cm})$, in optical contact to a zerodur rod. Its finesse is $\sim 60$ at $633 \mathrm{~nm}$ and $\sim 100$ at 778 nm. 


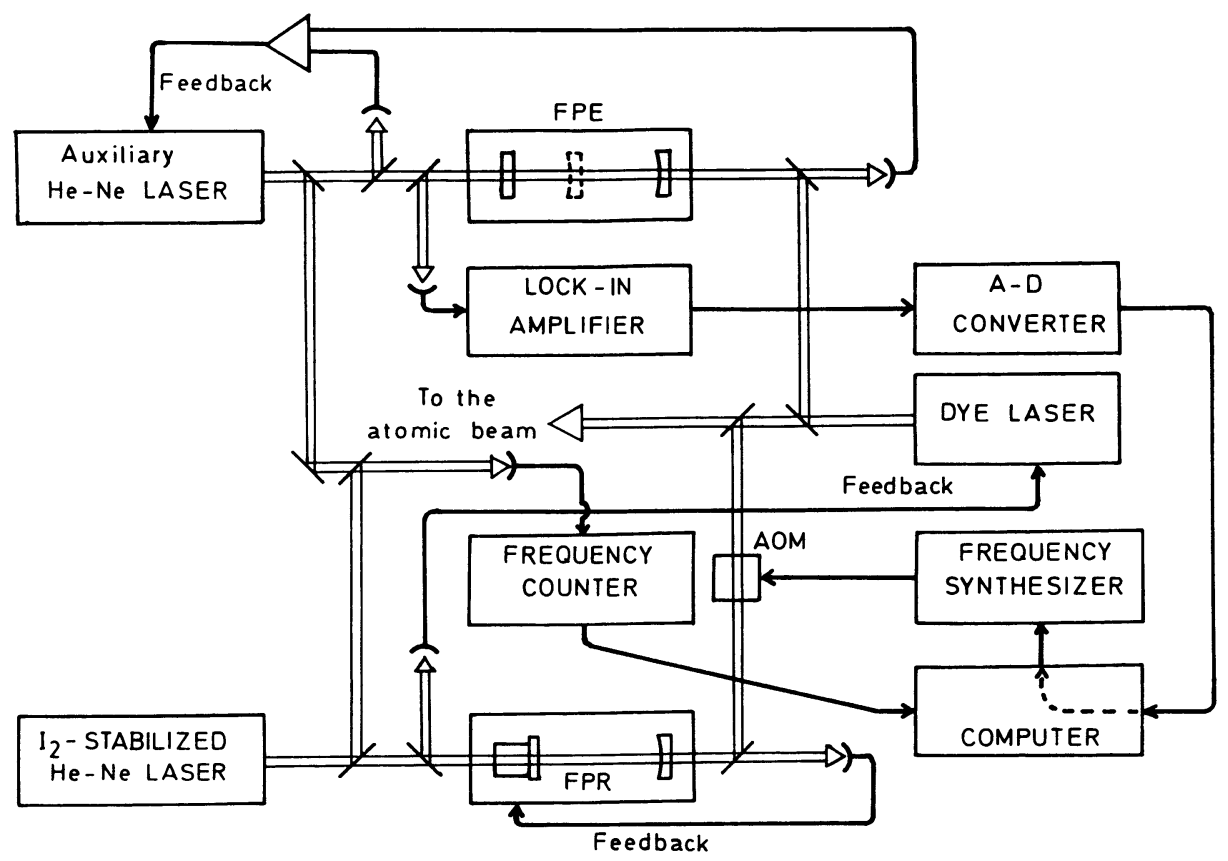

Fig. 1. - Experimental set-up for the wavelength comparison.

Figure 1 shows the experimental set-up for the wavelength comparison. As explained in paper I [2] , the dye laser frequency is known with respect to a reference Fabry-Perot cavity (FPR) which is locked to an $\mathrm{I}_{2}$-stabilized $\mathrm{He}-\mathrm{Ne}$ laser. The dye laser frequency is precisely scanned by means of an acousto-optic modulator in conjunction with a computer-controlled frequency synthesizer. With this apparatus we have precisely measured the frequency difference $f_{2 p}$ between the two-photon transition frequency and the Airy peaks of the reference cavity [3] . Figure 2 shows the relative position of the atomic signal with respect to the Airy peaks of the reference cavity FPR and of the Fabry-Perot etalon FPE. For the wavelength comparison we have to measure the frequency difference $\Delta_{R}$ between the iodine $f$ component and the closest peak of the FPE. For that purpose an auxiliary He-Ne laser is mode-matched and locked to the FPE cavity. The beat frequency between the auxiliary and the standard He-Ne laser is measured by a frequency counter. We have also to measure the frequency difference $\Delta_{\mathrm{IR}}$ between the two-photon signal and the closest peak $N_{\mathrm{IR}}$ of the FPE cavity. We have $\Delta_{\mathrm{IR}}=f_{2 \mathrm{p}}+f_{\mathrm{FP}}$, where $f_{\mathrm{FP}}$ is the frequency difference between a given Airy peak of the reference cavity FPR and one of the etalon cavity FPE (Fig. 2). In order to measure the frequency $f_{\mathrm{FP}}$, the dye laser is scanned to the resonance with the etalon cavity FPE, and mode-matched to this cavity. Its frequency is locked to the etalon cavity through the computer. The dye laser frequency is modulated (about $1 \mathrm{MHz}$ peak-to-peak at $1.2 \mathrm{kHz}$ ) and the modulation of the transmitted beam is detected by a lock-in amplifier. After conversion by an analog-digital converter, the signal is read by the computer, which drives the acousto-optic modulator in order to cancel the output of the lock-in amplifier. During the measurement (about 2 minutes), the computer records simultaneously $f_{\mathrm{FP}}$ (twice the frequency of the acousto-optic modulator) and $\Delta_{\mathrm{R}}$. Though the etalon cavity FPE is temperature stabilized, there is a residual 
fluctuation of the length of this cavity and $f_{\mathrm{FP}}$ and $\Delta_{\mathrm{R}}$ fluctuate. These fluctuations are correlated and, in order to eliminate them, the computer calculates the quantity :

$$
f_{\mathrm{FP}}(\text { corrected })=f_{\mathrm{FP}}-\frac{N_{\mathrm{IR}}}{N_{\mathrm{R}}}\left(\Delta_{\mathrm{R}}-\Delta_{\mathrm{R}}^{0}\right)
$$

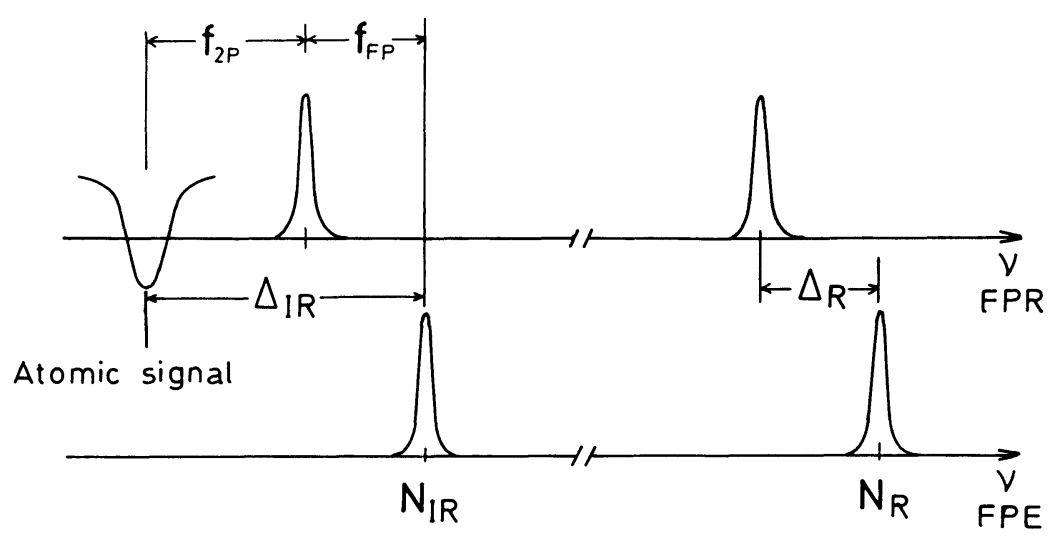

Fig. 2. Relative position of the two-photon signal with respect to the Airy peaks of the reference cavity and of the etalon cavity.

This quantity is independent of the length fluctuations of the etalon cavity FPE and corresponds to the $f_{\mathrm{FP}}$ value obtained when $\Delta_{\mathrm{R}}=\Delta_{\mathrm{R}}^{0}\left(\Delta_{\mathrm{R}}^{0}\right.$ is a fixed value, close to the experimental one and arbitrarily fixed).

To obtain a precise wavelength measurement, it is necessary that the frequencies of the dye laser and of the auxiliary He-Ne laser coincide with the resonance frequencies of the etalon cavity FPE. To take into account the intensity variation due to the gain curve of the auxiliary $\mathrm{He}-\mathrm{Ne}$ laser, we monitor the difference between the transmitted beam through the etalon cavity and a reference beam having the same intensity. We have tested the efficiency of this procedure by locking the auxiliary He-Ne laser to two adjacent peaks $N_{R}$ and $N_{R}-1$ of the etalon FPE. By this means we obtain a measurement of the free spectral range of this cavity (frequency measurement) which can be compared with the most precise value obtained by interferometry (wavelength measurement). As explained in the following, we have used two etalon cavity lengths, $10 \mathrm{~cm}$ and $50 \mathrm{~cm}$. The comparison between the two free spectral range measurements is given in table I. A systematic discrepancy appears in the short etalon measurements. In this case we reach the limit of the differential method used to eliminate the gain curve effect because the two Airy peaks of the etalon cavity are in the wings of this curve. In our wavelength measurements we have used the mean of the two results obtained when the auxiliary He-Ne laser is locked to the $N_{R}$ and $N_{R}-1$ peaks. We estimate the error in the control loop of the He-Ne laser frequency on the short etalon cavity to be $\pm 9 \mathrm{kHz}$ (half the difference between the two free spectral range measurements). Taking into account the virtual mirrors procedure, which will be explained in the following, this error introduces an uncertainty of $4.7 \times 10^{-12}$ in the final result. Measurement with the long cavity etalon always involves an Airy peak at the top of the He-Ne gain curve and our differential method is more efficient. In this case we estimate the error in the He-Ne laser frequency to be $\pm 0.5 \mathrm{kHz}$, 
corresponding to an uncertainty of $1.3 \times 10^{-12}$ in the final result. The same kind of error can exist for the dye laser frequency servo-loop. Nevertheless these errors can be neglected because i) the finesse of the etalon cavity is larger in the infrared domain than in the red one; ii) there is no dependence of the dye laser intensity versus the dye laser frequency (we have verified that the signal at the modulation frequency of the dye laser frequency is negligible).

Table I. - Free spectral range measurment of the etalon cavity FPE.

\begin{tabular}{|l|c|c|}
\hline & $\begin{array}{c}\text { Interferometric } \\
\text { measurement }\end{array}$ & $\begin{array}{c}\text { Frequency } \\
\text { measurement }\end{array}$ \\
\hline Short cavity & $1497.3200 \mathrm{MHz}$ & $1497.302(5) \mathrm{MHz}$ \\
Long cavity & $299.7006 \mathrm{MHz}$ & $299.699(5) \mathrm{MHz}$ \\
\hline
\end{tabular}

2.3 VIRTUAL MIRRORS METHOD. - The frequencies of the red and infrared radiations inside the etalon cavity FPE are determined by the resonant condition:

$$
\nu=\frac{c}{2 L}(N+\psi+\Phi)
$$

where $L$ is the cavity length, $N$ is an integer number, $\psi$ is the reflective phase shift for the light of frequency $\nu$ and $\Phi$ the Fresnel phase shift. The Fresnel phase shift depends only on the cavity geometry. Its measurement will be described in the following. The reflective phase shift $\psi$ due to the mirror coating is wavelength dependent and is eliminated by the method of virtual mirrors by using alternately two rods of different lengths $(10 \mathrm{~cm}$ and $50 \mathrm{~cm})$ for the etalon cavity. This method is explained in detail in reference [7]. The basic idea is that the reflective phase shift $\psi$ is independent of the cavity length. We can write the resonant condition (1) for the long and the short cavity (labelled $\ell$ and $\mathrm{s}$ respectively) and for the red and infrared radiations ( $R$ and $I R$ labels) which are compared. For example, we have for the long etalon and for the infrared frequency:

$$
\nu_{\mathrm{IR}}=\frac{c}{2 L^{\ell}}\left(N_{\mathrm{IR}}^{\ell}+\psi_{\mathrm{IR}}+\Phi^{\ell}-\delta_{\mathrm{IR}}^{\ell}\right)
$$

where $\delta_{\mathrm{IR}}^{\ell}$ is the fractional order relative to the higher frequency Airy peak. It is the ratio between the frequency splitting $\Delta_{\mathrm{IR}}^{\ell}$ (see Fig. 2) and the free spectral range $\frac{c}{2 L^{\ell}}$. From the equations (2) relative to the short and long etalon and to the two radiations, we can eliminate the two cavity lengths and the reflective phase shifts $\psi_{\mathrm{IR}}$ and $\psi_{\mathrm{R}}$. We obtain the ratio between the two frequencies:

$$
\frac{\nu_{\mathrm{IR}}}{\nu_{\mathrm{R}}}=\frac{\left(N_{\mathrm{IR}}^{\ell}-N_{\mathrm{IR}}^{\mathrm{s}}\right)+\left(\Phi^{\ell}-\Phi^{\mathrm{s}}\right)-\left(\delta_{\mathrm{IR}}^{\ell}-\delta_{\mathrm{IR}}^{\mathrm{s}}\right)}{\left(N_{\mathrm{R}}^{\ell}-N_{\mathrm{R}}^{\mathrm{s}}\right)+\left(\Phi^{\ell}-\Phi^{\mathrm{s}}\right)-\left(\delta_{\mathrm{R}}^{\ell}-\delta_{\mathrm{R}}^{\mathrm{s}}\right)}
$$

We have made the wavelength measurements in three steps, first with the $10 \mathrm{~cm}$ spacer, then with the $50 \mathrm{~cm}$ one and finally with the $10 \mathrm{~cm}$ spacer again. When we change the cavity length, we have to break the vacuum which results in a slight ageing of the mirrors, due to the air exposure, with 
consequent changes of $\psi_{\mathrm{R}}$ and $\psi_{\mathrm{IR}}$. The difference between the two reflective phase shifts $\psi_{\mathrm{R}}$ and $\psi_{\mathrm{IR}}$ can be considered as a variation $\delta L$ of the cavity optical length for the red and infrared radiations. For the infrared radiation, the mirrors are more reflective than for the red one and the cavity optical length is shorter. From our wavelength measurements with the $10 \mathrm{~cm}$ etalon cavity FPE, we can deduce $\delta L$ at the beginning and at the end of the experiment. The results are given in table II. As the hydrogen and deuterium wavelengths are very close we have taken the mean of the hydrogen and deuterium results relative to the same $2 S-n D$ two-photon transition. We have observed a slight variation of $\delta L$ (about $0.03 . \mathrm{nm}$ ) during the experiment and we take this effect into account in the uncertainty of our final result.

Table II. - Variation of the cavity optical length between the red and infrared radiation at the beginning and at the end of the experiment.

\begin{tabular}{|c|c|c|}
\hline $\begin{array}{c}2 \delta L \\
\text { (Wave length in } \mathrm{nm})\end{array}$ & $\begin{array}{c}\text { First measuremement } \\
\text { with the } 10 \mathrm{~cm} \text { etalon } \\
(\mathrm{nm})\end{array}$ & $\begin{array}{c}\text { Last measurement } \\
\text { with the10 cm etalon } \\
(\mathrm{nm})\end{array}$ \\
\hline $2[L(633)-L(778)]$ & $3.028(36)$ & $3.079(36)$ \\
$2[L(633)-L(760)]$ & $2.763(36)$ & $2.780(36)$ \\
$2[L(633)-L(750)]$ & $2.610(36)$ & $2.639(36)$ \\
\hline
\end{tabular}

2.4 FRESNEL PHASE SHIFT MEASUREMENT. - For a planè-spherical Fabry-Perot, the Fresnel phase shift depends on the length of the cavity and on the curvature $R$ of the spherical mirror [8] :

$$
\Phi=\frac{1}{\pi} \cos ^{-1}\left(1-\frac{L}{R}\right)^{1 / 2}
$$

We have determined the Fresnel phase shift by measuring the frequency interval between the fundamental $\mathrm{TEM}_{00}$ mode and the first transverse mode $\mathrm{TEM}_{01}$ (or $\mathrm{TEM}_{10}$ ) of the cavity. Indeed, the resonance condition for the $\mathrm{TEM}_{n, m}$ mode is [8] :

$$
\nu=\frac{c}{2 L}[N+\psi+(n+m+1) \Phi]
$$

We can deduce

$$
\Phi=\frac{2 L}{c}\left[\nu\left(\mathrm{TEM}_{01}\right)-\nu\left(\mathrm{TEM}_{00}\right)\right]
$$

In principle $\mathrm{TEM}_{01}$ and $\mathrm{TEM}_{10}$ are degenerate by symmetry. However, due to imperfections in the mirror curvature, they are not completely degenerate. Depending on the alignment of the laser beam with respect to the FPE optical axis, we may excite various superpositions of these two 
modes which give different results for the relative frequency of the first transverse mode and the $\mathrm{TEM}_{00}$ mode. We have made measurements for various alignments and the result is shown in figure 3, which shows the dependence of this frequency difference upon the orientation of the two transmitted light spots of the TEM $\mathrm{T}_{01}$ mode. The Fresnel phase-shift that we need is then given by the mean value of the curve of figure 3 [9]. We have made this measurement for each step of the experiment $(10 \mathrm{~cm}, 50 \mathrm{~cm}$ and $10 \mathrm{~cm}$ etalon) with the $\mathrm{He}-\mathrm{Ne}$ laser. For the $50 \mathrm{~cm}$ etalon, we have also made the measurement with the dye-laser at $780 \mathrm{~nm}$. The results are given in table III. We have observed a significant variation between the two $10 \mathrm{~cm}$ etalon measurements. This is due to the fact that we do not use exactly the same points of the mirrors in the two cases. On the other hand, the two $50 \mathrm{~cm}$ etalon measurements are in very good agreement : the variation with the wavelength of the size of the laser beam inside the cavity has a negligible effect.

Table III. - Frequency difference $(\mathrm{MHz})$ between the fundamental mode $\mathrm{TEM}_{00}$ and the first transverse mode $\mathrm{TEM}_{01}$.

$\begin{array}{ll}10 \mathrm{~cm} \text { etalon (first measurment, } 633 \mathrm{~nm}) & : 200.776(67) \\ 50 \mathrm{~cm} \text { etalon }(633 \mathrm{~nm}) & : 109.851(13) \\ 50 \mathrm{~cm} \text { etalon }(780 \mathrm{~nm}) & : 109.853(13) \\ 10 \mathrm{~cm} \text { etalon (last measurement, } 633 \mathrm{~nm}) & : 201.024(49)\end{array}$

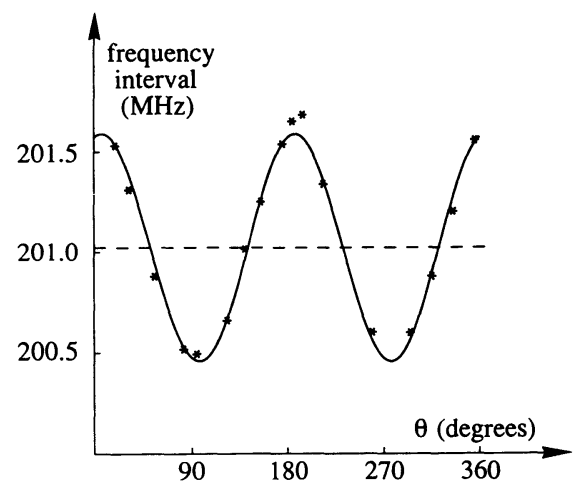

Fig. 3. - Frequency difference between the first transverse modes $T E M_{01}$ and $\mathrm{TEM}_{10}$ and the fondamental mode $\mathrm{TEM}_{00} v$ s. the orientation of the two spots of the transverse modes.

2.5 RESULTS. - We used equation (3) to determine the infrared radiation frequency. In the two preceding paragraphs we have described the measurements of the Fresnel phase shift $\Phi$ and of the fractional order $\delta$. The integer numbers $N$ are determined by the method of excess fractions [10] . In order to apply this method we use as known wavelengths the $f$ component of the $\mathrm{I}_{2}-$ 
stabilized He-Ne laser and the six two-photon transition wavelengths which are measured. Indeed, taking into account our earlier determination of the Rydberg constant [11], these wavelengths are known with a relative uncertainty better than $10^{-9}$. Since the uncertainty in a fractional order measurement is about $10^{-4}$ in the case of the $50 \mathrm{~cm}$ etalon and is smaller for the $10 \mathrm{~cm}$ etalon, and since the etalon length is initially known with a relative uncertainty of about $10^{-3}$, the fractional order data for these seven wavelengths are sufficient to determine unambiguously the integer number $N$. The values of $N$ are given in table IV.

Table IV. - Values of the integer numbers $N$.

\begin{tabular}{|c|c|c|}
\hline Transition & $50 \mathrm{~cm}$ etalon & $10 \mathrm{~cm}$ etalon \\
\hline He - Ne f component & 1580284 & 316306 \\
Deuterium 2S-12D & 1333679 & 266946 \\
Hydrogen 2S - 12D & 1333316 & 266873 \\
Deuterium 2S - 10D & 1316913 & 263590 \\
Hydrogen 2S - 10D & 1316555 & 263518 \\
Deuterium 2S - 8D & 1286048 & 257412 \\
Hydrogen S - 8D & 1285698 & 257342 \\
\hline
\end{tabular}

As we have two sets of data for the $10 \mathrm{~cm}$ etalon, we can apply equation (3) twice (firstly : first $10 \mathrm{~cm}$ data and $50 \mathrm{~cm}$ data; secondly : $50 \mathrm{~cm}$ data and last $10 \mathrm{~cm}$ data). The results for the six studied transitions are given in table $V$. The second column gives the difference betwoen the second and the first determinations. This difference is due to the ageing of the mirrors. The third column gives the mean of the two results. This is the value that we have adopted. The quoted uncertainty does not include the reference laser uncertainty. It is the quadratic sum of : i) the uncertainty of the comparison between the He-Ne lasers (about $10^{-11}$ ), ii) the uncertainty of the atomic frequencies (statistical uncertainty and uncertainty of the theoretical lineshape as explained in [3] ), iii) the uncertainty of the Fresnel phase shift measurements (about $1.2 \times 10^{-11}$ ), iv) the statistical uncertainty of the fractional order measurements and v) the uncertainty due to the ageing of the mirrors (half the value of the first column of Tab. V). A more detailed analysis of the uncertainties will be given in section 3 .

\section{Rydberg constant determination.}

3.1 Determination of THE $2 \mathrm{~S}_{1 / 2}-n \mathrm{D}_{5 / 2}$ ATOMIC SPLITTING. - To determine the $2 \mathrm{~S}_{1 / 2}-$ $n \mathrm{D}_{5 / 2}$ atomic splitting from the frequency measurements reported in table $\mathrm{V}$, we have to make several corrections. These corrections are given in table VI.

i) Second order Doppler effect. This correction has been discussed in paper II [3] . As we have measured the velocity distribution in the metastable atomic beam, we can calculate precisely the second-order Doppler effect for hydrogen and deuterium.

ii) $2 \mathrm{~S}_{1 / 2}$ hyperfine splitting. As we have measured only the most intense hyperfine component, we have to take into account the hyperfine splitting of the $2 S_{1 / 2}$ metastable state. This splitting 
Table V. - Resonance frequencies of the two-photon transitions (column 3) and difference (D) between the last and the first measurements (column 2).

\begin{tabular}{|c|c|r|}
\hline & $D(\mathrm{MHz})$ & Mean value $(\mathrm{MHz})$ \\
\hline $\mathrm{H}: 2 \mathrm{~S}_{1 / 2}(F=1)-8 \mathrm{D}_{5 / 2}$ & 0.025 & $385324758.668(24)$ \\
$\mathrm{D}: 2 \mathrm{~S}_{1 / 2}(F=3 / 2)-8 \mathrm{D}_{5 / 2}$ & 0.025 & $385429619.684(21)$ \\
$\mathrm{H}: 2 \mathrm{~S}_{1 / 2}(F=1)-10 \mathrm{D}_{5 / 2}$ & 0.008 & $394572421.089(16)$ \\
$\mathrm{D}: 2 \mathrm{~S}_{1 / 2}(F=3 / 2)-10 \mathrm{D}_{5 / 2}$ & 0.008 & $394679798.383(16)$ \\
$\mathrm{H}: 2 \mathrm{~S}_{1 / 2}(F=1)-12 \mathrm{D}_{5 / 2}$ & 0.013 & $399595841.575(22)$ \\
$\mathrm{D}: 2 \mathrm{~S}_{1 / 2}(F=3 / 2)-12 \mathrm{D}_{5 / 2}$ & 0.013 & $399704585.764(20)$ \\
\hline
\end{tabular}

Table VI. - Corrections for the second-order Doppler effect and the hyperfine splittings (MHz).

\begin{tabular}{|c|c|c|c|}
\hline Transition & $\begin{array}{c}\text { Doppler } \\
\text { effect }\end{array}$ & $\begin{array}{c}2 \mathrm{~S}_{1 / 2} \text { hyperfine } \\
\text { splitting }\end{array}$ & $\begin{array}{c}n \mathrm{D}_{5 / 2} \text { hyperfine } \\
\text { splitting }\end{array}$ \\
\hline $\mathrm{H}: 2 \mathrm{~S}_{1 / 2}-8 \mathrm{D}_{5 / 2}$ & 0.040 & 44.389 & -0.028 \\
$\mathrm{D}: 2 \mathrm{~S}_{1 / 2}-8 \mathrm{D}_{5 / 2}$ & 0.017 & 13.641 & -0.008 \\
$\mathrm{H}: 2 \mathrm{~S}_{1 / 2}-10 \mathrm{D}_{5 / 2}$ & 0.041 & 44.389 & -0.014 \\
$\mathrm{D}: 2 \mathrm{~S}_{1 / 2}-10 \mathrm{D}_{5 / 2}$ & 0.017 & 13.641 & -0.004 \\
$\mathrm{H}: 2 \mathrm{~S}_{1 / 2}-12 \mathrm{D}_{5 / 2}$ & 0.041 & 44.389 & -0.008 \\
$\mathrm{D}: 2 \mathrm{~S}_{1 / 2}-12 \mathrm{D}_{5 / 2}$ & 0.017 & 13.641 & -0.002 \\
\hline
\end{tabular}

is very well known for hydrogen [12] and deuterium [13] and the corresponding corrections are $+44.389 \mathrm{MHz}$ and $+13.641 \mathrm{MHz}$ respectively.

iii) $n \mathrm{D}_{5 / 2}$ hyperfine splitting. We do not resolve the hyperfine structure of the $n \mathrm{D}_{5 / 2}$ state. This splitting can be calculated with the Fermi formula [14] . For example we obtain $142.6 \mathrm{kHz}$ for the $8 D_{5 / 2}$ level in hydrogen. As the initial level of the two-photon transition is a particular hyperfine level (for instance $F_{i}=1$ for hydrogen), the intensities of the two hyperfine transitions $2 \mathrm{~S}_{1 / 2}\left(F_{i}=1\right)-n \mathrm{D}_{5 / 2}\left(F_{f}\right)\left(F_{f}=2\right.$ and $F_{f}=3$ for hydrogen) are not proportional to the degeneracy $2 F_{f}+1$ of the excited hyperfine level but to :

$$
\left(2 F_{f}+1\right)\left\{\begin{array}{ccc}
5 / 2 & 1 / 2 & 2 \\
F_{i} & F_{f} & I
\end{array}\right\}^{2}
$$

This effect shifts the line and the corresponding corrections are listed in table VI. 
3.2 CALCULATION OF THE RYDBERg CONSTANT. - The corrections given in table VI lead to six values of the $2 S_{1 / 2}-n D_{5 / 2}$ splittings corresponding to the six transitions investigated. We have used the experimental value of the hydrogen 2S Lamb shift (1057.851(2) MHz [15] ) and the theoretical value (1057.229 MHz) of the deuterium one, calculated using reference [16], to deduce the $2 \mathrm{P}_{1 / 2}-n \mathrm{D}_{5 / 2}$ frequencies. We have then compared these frequencies to those reported by Erickson [17] after correction for the 1986 recommended values of the fine structure constant, the proton/electron, and the deuteron/proton mass ratios [18] :

$$
\begin{gathered}
\alpha^{-1}=137.0359895(61) \\
m_{\mathrm{p}} / m_{\mathrm{e}}=1836.152701(37) \\
m_{\mathrm{D}} / m_{\mathrm{p}}=1.999007496(6)
\end{gathered}
$$

The measured frequencies lead to six independent determinations of the Rydberg constant given in table VII. The quoted uncertainties do not include the reference laser uncertainty. As can be seen from this table, our six independent measurements of $R_{\infty}$ are quite self-consistent. Taking into account the reference laser uncertainty, our final result is:

$$
R_{\infty}=109737.315709(18) \mathrm{cm}^{-1}
$$

Table VII. - Determination of the Rydberg constant.

$$
\begin{array}{cl} 
& \text { Transition } \\
H: & 2 S_{1 / 2}-8 D_{5 / 2} \\
D: & 2 S_{1 / 2}-8 D_{5 / 2} \\
H: & 2 S_{1 / 2}-10 D_{5 / 2} \\
D & : 2 S_{1 / 2}-10 D_{5 / 2} \\
H: & 2 S_{1 / 2}-12 D_{5 / 2} \\
D: & 2 S_{1 / 2}-12 D_{5 / 2}
\end{array}
$$

Final result
Measured frequency $(\mathrm{MHz})$

$770649561.737(49)$

$770859253.018(43)$

$789144886.593(35)$

$789359610.420(34)$

$799191727.573(47)$

$799409185.184(42)$

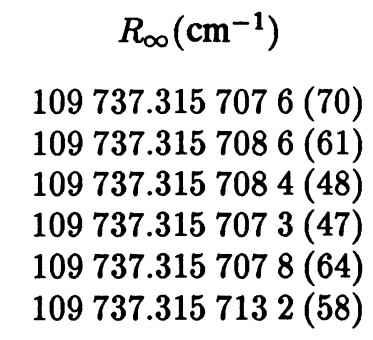

109737.3157088 (47)

The precision is $1.7 \times 10^{-10}$ and $4.3 \times 10^{-11}$ with respect to our reference laser. This result is slightly smaller (about $4.4 \times 10^{-11}$ ) than our preliminary result published in 1988 [19]. This is due to three reasons:

i) The second-order Doppler effect correction has been calculated with the measured velocity distribution and not with an a priori one (correction of about $-0.6 \times 10^{-11}$ )

ii) The Rydberg constant calculation was made with an old value of the fine structure constant $\alpha^{-1}=137.03604$ (correction of about $-1.3 \times 10^{-11}$ )

iii) The determination of the two-photon transition position was deduced from a linear extrapolation to null light power of the half-maximum center of the line and not from the light-shift corrected line position as explained in reference 3 (correction of about $-2.5 \times 10^{-11}$ ). 
Table VIII. - Comparison with other recent measurements.

$\begin{array}{cc} & \left(R_{\infty}-109737\right) \mathrm{cm}^{-1} \\ \text { Goldsmith } \text { et al. [20] } & 0.31500(32) \\ \text { Petley } \text { et al. [21] } & 0.31521(64) \\ \text { Aminet al. [22] } & 0.31544(11) \\ \text { Hildum } \text { etal. [25] } & 0.31492(21) \\ \text { Barr etal. [26] } & 0.31500(110) \\ \text { Biraben } \text { et al. [11] } & 0.31569(6) \\ \text { Zhao } \text { et al. [23] } & 0.31569(7) \\ \text { Zhao } \text { et al. [24] } & 0.31573(3) \\ \text { Beausoleilet al. [27] } & 0.31571(7) \\ \text { Boshier } \text { et al. [28] } & 0.31573(3) \\ & \\ \text { Present result } & 0.315709(17)\end{array}$

These values are all corrected using the new definition of $c$ and the experimental ratio $m_{\mathrm{e}} / m_{\mathrm{p}}$.

In table VIII our result is compared to our previous one [11] and to those obtained by different groups since 1978 from excitation either of the Balmer- $\alpha$ and $-\beta$ transitions [20-24] or of the 1S-2S transition [25-28]. Since our 1986 measurement there is a very good agreement which is illustrated in figure 4.

3.3 UNCERTAINTIES ANALYSIS. - The various contributions to the total uncertainty are listed in table IX. In this table the first two items do not come from our experiment and give the present limitation to the method (about $1.9 \times 10^{-11}$ ). For hydrogen the $2 S$ Lamb shift experimental uncertainty is $2 \mathrm{kHz}$ [15] . Nevertheless, taking into account another less precise measurement [29] $(1057.845$ (9) $\mathrm{MHz}$ ), we have adopted a $10 \mathrm{kHz}$ uncertainty for the hydrogen $2 \mathrm{~S}$ Lamb shift measurement. As the Q.E.D. uncertainty of the $2 \mathrm{P}_{1 / 2}$ level energy calculation is about $3 \mathrm{kHz}$ [17] , the total uncertainty due to the Lamb shift and the energy level calculations is about $1.5 \times 10^{-11}$, which is the value indicated in table IX. For deuterium the Lamb shift calculation uncertainty is $\approx$ $14 \mathrm{kHz}$ (quadratic sum of the $9 \mathrm{kHz}$ Q.E.D. uncertainty and of the $11 \mathrm{kHz}$ nuclear size uncertainty) and the total Lamb shift and energy calculations uncertainty is $\approx 1.8 \times 10^{-11}$.

In table IX the other items depend upon our experiment. The statistical uncertainty is the standard deviation of our six independent results. The Stark effect, second-order Doppler effect and theoretical lineshape uncertainties have been discussed in paper II [3] . In comparison with our previous measurement [11] the improvement in the Stark effect uncertainty is checked by the study of the 2S-20D two-photon transition which gives an upper limit $(2 \mathrm{mV} / \mathrm{cm})$ to the stray electric fields. The uncertainties due to the ageing of the mirrors, to the Fresnel phase shift measurement and to the comparison between the He-Ne lasers have been discussed in this paper. Finally the more important uncertainty is due to the standard laser $\left(1.6 \times 10^{-10}\right)$. With respect to the standard laser, our precision is $4.3 \times 10^{-11}$. 


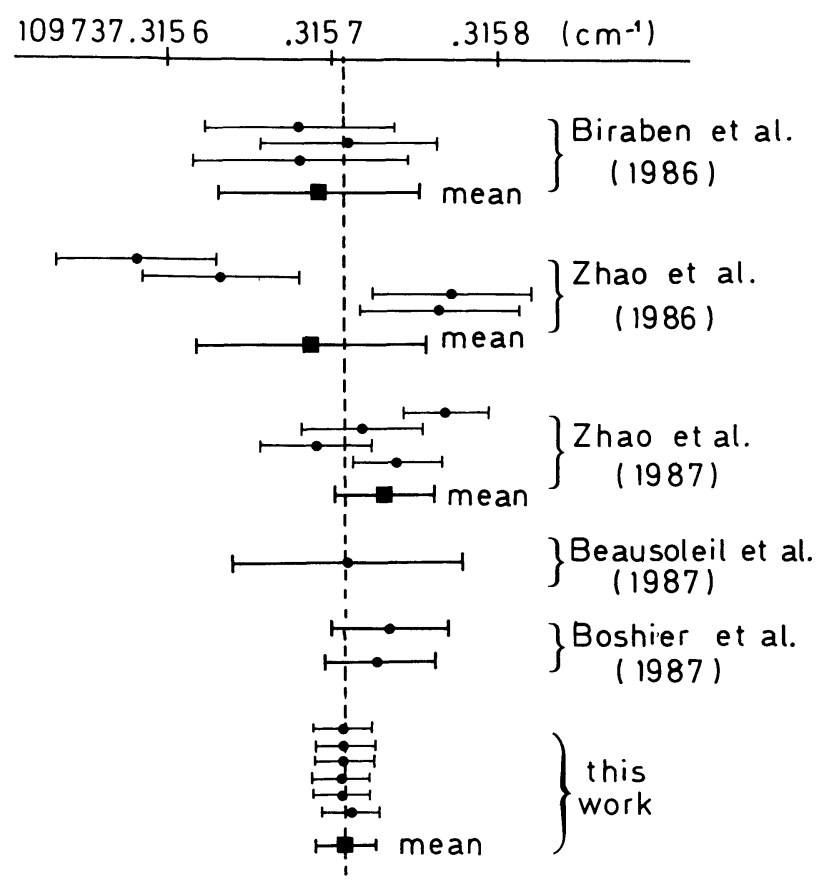

Fig. 4. - Comparison of our result with recent high precision measurements of the Rydberg constant.

TABLE IX. - Uncertainties (part in $10^{11}$ ).

Electron-to-proton mass ratio

Lamb-shift and energy-level calculations $\quad 1.5$

$\begin{array}{lr}\text { Stark effect } & 0.5\end{array}$

Second-order Doppler effect $\quad 0.5$

Uncertainty of the theoretical lineshape $\quad 2.0$

$\begin{array}{lr}\text { Statistical } & 2.0 \\ \text { Ageingof } & 2.0\end{array}$

$\begin{array}{ll}\text { Ageing of the mirrors } & 2.0\end{array}$

Fresnel phase-shift measurement $\quad 1.2$

Comparison between the He-Ne lasers $\quad \underline{1.0}$

Root-mean-square uncertainty 4.3

Standard laser $\quad \underline{16.0}$

$\begin{array}{ll}\text { Final uncertainty } & 16.6\end{array}$

3.4 IsoTOPIC SHIFTS. - Our experiment also provides three isotopic shifts which are given in table X. The quoted uncertainties are much smaller than those on each $2 S_{1 / 2}-n D_{5 / 2}$ measurement, since various systematic errors cancel. From these three isotopic shifts, we can deduce three independent measurements of the proton/electron mass ratio. Our mean value : $m_{\mathrm{p}} / m_{\mathrm{e}}=$ $1836.15259(24)$ is in excellent agreement with the more precise one $m_{\mathrm{p}} / m_{\mathrm{e}}=1836.152701(37)$ of Van Dyck et al. [30] . The uncertainty of our measurement is the rms sum of the following contributions : statistical $\left(1.1 \times 10^{-7}\right)$, proton/deuteron mass ratio $\left(3 \times 10^{-9}[18]\right)$, nuclear size 
$\left(6.3 \times 10^{-8}\right)$ and second-order Doppler effect $\left(2 \times 10^{-8}\right)$. Figure 5 shows the comparison of our result with other recent measurements [30-33].

Table X. - Isotopic shifts.

$\begin{array}{lll}\text { Transition } & \text { Isotopic shift (MHz) } & m_{\mathrm{p}} / m_{\mathbf{e}} \\ & & \\ \text { 2S - 8D } & 209691.281(39) & 1836.15264 \\ \text { 2S - 10D } & 214723.827(33) & 1836.15277 \\ \text { 2S - 10D } & 217457.611(43) & 1836.15237\end{array}$

Mean $1836.15259(24)$

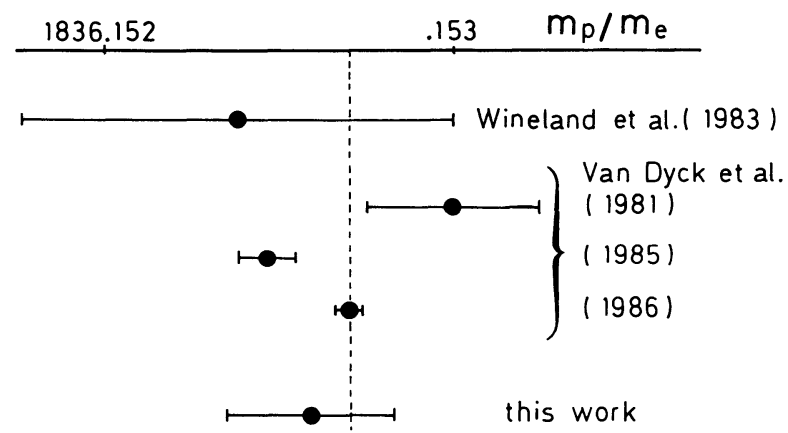

Fig. 5. - Comparison of our result with recent determinations of the proton/electron mass ratio.

\section{Conclusion.}

We have made a new measurement of the Rydberg constant, the most precise one at the present time. It is limited by the precision of the wavelength and frequency standard in the visible range. This shows that the present realization of the meter is no longer satisfactory in the optical domain and that more precise frequency standards are required.

\section{Acknowledgements.}

The authors are indebted to Prof. B. Cagnac for much fruitful advice during this experiment. We thank Drs P. Juncar and Y. Millerioux from the Institut National de Métrologie for the loan of a reference laser and Mr. G. Ancourt from Stigma Optique for preparing the optical contact of our 
etalon. This work is partially supported by the Bureau National de Metrologie. One of us (JCG) is grateful to the Brazilian Financial Agency CAPES for a scholarship.

\section{References}

[1] Biraben F., Garreau J.C., JULIEN L. and Allegrini M., Phys. Rev. Lett. 62 (1989) 621.

[2] GarReaU J.C., Allegrini M., JUlien L. and Biraben F., part I, J. Phys. France 51 (1990) 2263.

[3] GARREAU J.C., ALLEgrini M., JULIEN L. and BIRABEN F., part II, J. Phys. France 51 (1990) 2275.

[4] JENNINGS D.A., POLlOCK C.R., PETERSEN F.R., DRullingER R.E., EVENSON K.M., Wells J.S., HALl J.L. and LAYER H.P., Opt. Lett. 8 (1983) 136.

[5] Documents concerning the New Definition of the Metre, Metrologia 19 (1984) 163.

[6] MILLERIOUX Y., private communication.

[7] LAYER H.P., DESLATTES R.D. and SCHWEITZER Jr. W.G., Appl. Opt. 15 (1976) 734.

[8] KOGELNIK H. and LI T., Appl. Opt. 5 (1966) 1550.

[9] FABRE C., DE VOE R.G. and BREWER R.G., Opt. Lett. 11 (1986) 365.

[10] BORN M. and WOLF E., Principles of Optics - Pergamon Press (1959).

[11] BIRABEN F., GARREAU J.C. and JULIEN L., Europhys. Lett. 2 (1986) 925.

[12] HEBERLE J.W., REICH H.A. and KUSCH P., Phys. Rev. 101 (1952) 612.

[13] REICH H.A., HEBERLE J.W. and KUSCH P., Phys. Rev. 104 (1956) 1586.

[14] BETHE H.S. and SALPETER E.E., Quantum Mechanics of One and Two-Electron Atoms, Springer Verlag, Berlin (1957).

[15] PAL'ChIKov V.G., SoKolov YU. L. and YaKoVleV V.P., JETP Lett. 38 (1983) 418 ; Metrologia 21 (1985) 99.

[16 ERICKSON G.W. and GROTCH H., Phys. Rev. Lett. 60 (1988) 2611; 63 (1989) 1326.

[17] ERICKSON G.W., J. Phys. Chem. Ref. Data 6 (1977) 831.

[18] COHEN E.R. and TAYLOR B.N., Rev. Mod. Phys. 59 (1987) 1121.

[19] Allegrini M., Biraben F., CagnaC B., GarReau J.C. and Julien L., in The Hydrogen Atom, Eds. G.F. Bassani, T.W. Hănsch and M. Inguscio, Springer Verlag, Berlin (1989).

[20] GolDSMITH J.E.M., WEBER E.W. and HÄNSCH T.W., Phys. Rev. Lett. 41 (1978) 1525.

[21] PETLEY B.W., MORRIS K. and SHAWYER R.E., J. Phys. B 13 (1980) 3099.

(22] AMIN.S.R., CALDWELl C.D. and LICHTEN W., Phys. Rev. Lett.47 (1981) 1234

[23] ZHAO P., LICHTEN W., LAYER H.P. AND BERGQUIST J.C., Phys. Rev. A34 (1986) 5138.

[24] ZHAO P., LICHTEN W., LAYER H.P. and BERGQUIST J.C., Phys. Rev. Lett. 58 (1987) 1293.

[25] HiLdUM E.A., BOESL U., MCINTYRE D.H., BEAUSOlEIL R.G. and HĀNSCH T.W., Phys. Rev. Lett. 56 (1986) 576.

[26 BARR J.R.M., GiRKIN J.M., TOLCHARD J.M. and FERGuSON A.I., Phys. Rev. Lett. 56 (1986) 580.

[27] Beausoleil R.G., McINTYRE D.H., FOOT C.J., Hildum E.A., COUILlaUd B. and HÄNSCH T.W., Phys. Rev. A35 (1987) 4878.

[28] Boshier M.G., Baird P.E.G., Foot C.J., Hinds E.A., Plimmer M.D., STACEy D.N., SWAN J.B., TATE D.A., WARRINGTON D.M. and WoODGATE G.K., Nature 330 (1987) 463, and Phys. Rev. $A 40$ (1989) 6169.

[29] LUNDEEN S.R. and PIPKIN F.M., Phys. Rev. Lett. 46 (1981) 232.

[30] Van DYCK R.S. Jr., MOORE F.L., FARNHAM D.L. and SCHWINBERG P.B., Bull. Am. Phys. Soc. 31 (1986) 244.

[31] Van DYCK R.S. Jr. and SCHWINBERG P.B., Phys. Rev. Lett. 47 (1981) 395.

[32] Van DYCK R.S. Jr., MOORE F.L., FARNHAM D.L. and SCHWINBERG P.B., International Journal of Mass Spectrometry and Ion Processes 66 (1985) 327.

[33] Wineland D.J., Bollinger J.J. and ItANo W.M., Phys. Rev. Lett. 50 (1983) 628.

Cet article a êté imprimé avec le Macro Package "Editions de Physique Avril 1990". 